\title{
Immune responses in mice vaccinated with a DNA vaccine expressing a new elastase from Trichinella spiralis
}

\author{
Xin Zhuo Zhang, Xiang Yuan Sun, Ying Bai, Wen Wen Yue, Xin Yue, Yan Yan Song, Jing Cui and Zhong Quan Wang
}

Department of Parasitology, Medical College, Zhengzhou University, Zhengzhou, China

\begin{abstract}
The elastase, which belongs to the serine protease family, hydrolyses various proteins and may be involved in the parasite invasion. In this study, complete sequence of elastase-1 (TsE) the nematode Trichinella spiralis (Owen, 1835) was cloned into the plasmid pcDNA3.1 as TsE DNA vaccine. After intramuscular vaccination, serum anti-Trichinella antibodies (IgG and subclass IgG1/ IgG2a, and IgA), total and specific intestinal mucosal sIgA in mice vaccinated with pcDNA3.1/TsE were measured by ELISA. The results showed that vaccination with pcDNA3.1/TsE induced a systemic humoral immune response (high levels of serum IgG and subclass IgG1/IgG2a and IgA) and local intestinal mucosal immune responses (high levels of TsE-specific sIgA). Vaccination of mice with TsE DNA vaccine also triggered a systemic and local concomitant Th1/Th2 response, as demonstrated by significant elevation of Th1 (IFN- $\gamma$ and IL-2) / Th2 (IL-4 and IL-10) cytokine levels after the spleen, mesenteric lymph node and Peyer's patch cells from vaccinated mice were stimulated with recombinant TsE (rTsE). The vaccination of mice with pcDNA3.1/TsE displayed a 17\% reduction of intestinal adult worms and a 39\% reduction of muscle larvae. Our results indicated that TsE DNA vaccine elicited a systemic concomitant Th1/Th2 response and an enteral local sIgA response, and produced a partial protection against infection with $T$. spiralis. The TsE may be regarded as a potential candidate vaccine target against Trichinella infection. The oral polyvalent vaccines should be developed to improve the protective efficacy of anti-Trichinella vaccines.
\end{abstract}

Keywords: Trichinella, trichinellosis, vaccination, protective immunity

Species of Trichinella Railliet, 1895 are intestinal and tissue-dwelling nematodes which can infect over 150 species of mammals, birds and reptiles over the world (Feidas et al. 2014). It has known that pigs and other domestic animals (horses, dogs, cats etc.) are the main natural hosts of Trichinella spiralis (Owen, 1835). Human with infection T. spiralis occurs when raw or uncooked meat containing encapsulated infective larvae is consumed. Trichinella spiralis is a severe public health threat and a tremendous hazard on animal food safety (Cui and Wang 2011, Cui et al. 2013a, Jiang et al. 2016, Rostami et al. 2017).

In the mainland China, the infected domestic pork is still the primary infectious source of human trichinellosis (Cui et al. 2011). It is difficult to prevent and control this zoonotic parasitosis because of its wide animal reservoirs, complicated life cycle and different state-specific antigens (Pozio 2007, Liu et al. 2015c). Until now, there are no effective preventive vaccines available for the food animal production (Zhang et al. 2018a). Hence, it is necessary to exploit anti-Trichinella vaccines to eliminate Trichinella infection in domestic pigs and block the transmission from pigs to humans (Li et al. 2015, 2018).

In recent years, some significant immune protection has been reported by suing DNA vaccines to prevent parasitic infections (Xu et al. 2017, Qi et al. 2018a, Wang et al. 2018). Furthermore, the DNA vaccine is easy to be constructed, prepared and administered. In our previous studies, a new elastase gene of T. spiralis (TsE, GenBank: XP_003377838.1), which belongs to the serine protease family, was obtained from the T. spiralis draft genome (Mitreva et al. 2011). It was cloned, expressed and purified in our laboratory. Bioinformatic analysis showed that complete TsE cDNA sequence was 1,350 bp encoding 449 amino acid with a weight of $47.3 \mathrm{kDa}$.

The TsE protein expression level at $T$. spiralis muscle larvae (ML) and intestinal infective larvae (IIL) stages was higher than those of other worm stages (Hu et al. 2020). The recombinant TsE (rTsE) facilitated the penetration of larvae into the in vitro intestinal epithelium cell (IEC) monolayer, whereas anti-rTsE antibodies and siRNA inhibited larval penetration of IEC (Zhang et al. 2020). The results suggested that the novel TsE might be a promising target molecule of vaccines against $T$. spiralis invasion of host's intestinal epithelia.

In the present study, the complete TsE cDNA sequence was cloned into the eukaryotic expression vector pcDNA3.1 and the pcDNA3.1/TsE was used to vaccinate BALB/c mice by intramuscular injection. The systematic and intestinal mucosal immune responses, and immune protection induced by vaccination using TsE DNA vaccine were ascertained. 


\section{MATERIALS AND METHODS}

\section{Worms and hosts}

Trichinella spiralis isolate (ISS534) used in this study was obtained from a domestic pig in central China and passaged in our laboratory (Wang et al. 2012). Female BALB/c mice (four weeks old) were purchased from the Zhengzhou University Experimental Animal Center (Zhengzhou, China), and fed in individual ventilated cages (IVC, Suzhou, China) (Cui et al. 2019). All animal experiment at procedures were authorised by the Life Science Ethics Committee, Zhengzhou University (No. SCXK 2017-0001).

\section{Collection of various life-cycle stages}

Muscle larvae (ML) were collected from infected mouse skeletal muscles at 42 days post-infection (dpi) by artificial digestion as previously reported (Jiang et al. 2012). The intestinal infective L1 larvae (IIL) recovered from the intestine of infected mouse at six hours post-infection (hpi) (Liu et al. 2015c). Adult worms (AW) were isolated from the intestine at $3 \mathrm{dpi}$ (Yang et al. 2015a). Female adults were cultured in RPMI- 1640 at $37^{\circ} \mathrm{C}$ in $5 \% \mathrm{CO}_{2}$ for $72 \mathrm{~h}$, and then newborn larvae (NBL) were harvested as described (Zhang et al. 2013, Wu et al. 2016).

\section{Preparation of rTsE and anti-rTsE serum}

Complete TsE gene was cloned and recombinant plasmid pQE-80L/TsE was transformed into Escherichia coli BL21 (Novagen) and induced by $1 \mathrm{mM}$ IPTG at $37^{\circ} \mathrm{C}$ for six hours (Liu et al. 2017). Recombinant TsE protein (rTsE) was purified with the aid of Ni-NTA-Sefinose resin (Sangon Biotech, Shanghai, China) in our laboratory (Hu et al. 2020). Fifteen mice were subcutaneously injected by $20 \mu \mathrm{g}$ rTsE mixed $1: 1(\mathrm{v} / \mathrm{v})$ with complete Freund's adjuvant. Two immunisation boosts were given as the same rTsE dosage with incomplete Freund' adjuvant at a two-weeks interval (Long et al. 2014, Sun et al. 2018b). At two weeks following the final immunisation, tail blood was taken and anti-rTsE sera were isolated (Cui et al. 2013b).

\section{Plasmid construction and sequence analysis of recombinant expression plasmids}

The total RNA from $T$. spiralis ML was extracted using Trizol (Invitrogen, USA), and reversely transcribed to the first strand cDNA (Hu et al. 2000). Complete TsE cDNA sequence (GenBank: XP_003377838.1) was obtained by PCR amplification with the following primers carrying Bam HI and XhoI(bold) (5'-CGGATCCGCCACCATGATCCTTTTCAAGTGC-3', 5'-CGGCTCGA GTTA ACGGAAAA AGGTG AAT GA-3).

The DNA encoding complete TsE was cloned into pcDNA3.1 as the TsE DNA vaccine (pcDNA3.1/TsE). In order to permit efficient initiation of translation, an artificial Kozak sequence (GCCACC) was incorporated into the sense primers (Liu et al. 2015a). The clones with expected size inserts were selected by restriction digestion and subjected to DNA sequencing. DNA and predicted amino acid sequences were analysed by Lasergene 7.1 software (DNASTAR Inc., Madison, Wisconsin, USA). The plasmid DNA was isolated using alkaline cleavage method (Tang et al. 2012).
RT-PCR and immunofluorescence test (IFT) for detecting TsE mRNA and protein expression in vitro

Baby hamster kidney cell 21 (BHK-21) were cultivated in culture plates (Nunc) with DMEM medium containing $100 \mathrm{U} / \mathrm{ml}$ penicillin, $100 \mu \mathrm{g} / \mathrm{ml}$ streptomycin and $10 \%$ fetal bovine serum at $37^{\circ} \mathrm{C}$ in $5 \% \mathrm{CO}_{2}$. When the cells were grown to $90 \%$ confluence, the cells were transfected by pcDNA3.1/TsE with a Lipofectamine 2000 (Invitrogen, USA) at $37^{\circ} \mathrm{C}$ for $48 \mathrm{~h}$. Total RNA was isolated from transfected cell and TsE mRNA expression was measured by RT-PCR with TsE-specific primers as mentioned above (Liu et al. 2015a). TsE protein expression in transfected BHK-21 cells was examined by IFT (Liu et al. 2018). In brief, BHK-21 were cultured up to cell monolayer and fixed using $4 \%$ formaldehyde for $20 \mathrm{~min}$. After washes with PBS, the cells were permeabilised using $0.1 \%$ TritonX-100 for $15 \mathrm{~min}$, blocked using $5 \%$ normal goat serum at $37^{\circ} \mathrm{C}$ for one hour, and incubated with anti-TsE serum $(1: 10)$ at $4{ }^{\circ} \mathrm{C}$ overnight. After washes with PBS, the cells were incubated with FITC-anti-mouse IgG conjugate (1 : 100; Santa Cruz, USA) at $37^{\circ} \mathrm{C}$ for one hour (Song et al. 2018a). The cells were re-dyed using 4', 6-diamidino-2-phenylindole (DAPI) for seven min. The cells were examined on fluorescence microscopy (Olympus, Tokyo, Japan) (Long et al. 2015, Xu et al. 2018).

\section{Vaccination regime and sample collection}

One hundred and eighty mice were divided into three groups (60 animals per group). Pre-immune serum samples (normal serum) were obtained via tail bleeding before the first vaccination (Liu et al. 2015a). Three days before vaccination, all mice were first injected in left and right quadriceps with $25 \mu 1$ of $5 \%$ bupivacaine hydrochloride. All mice were vaccinated through bilateral intramuscular injection into the quadriceps three times with different time interval. Each mouse of vaccine group was injected with $100 \mu \mathrm{g}$ pcDNA3.1/TsE in $100 \mu \mathrm{l}$ sterile PBS at each vaccination. As negative and blank control, mice were injected with 100 $\mu \mathrm{g}$ empty plasmid pcDNA3.1 or $100 \mu \mathrm{l}$ PBS alone. At weeks 0,4 , 6 and 8 post-vaccination, ten mice of each group were sacrificed. Serum, spleen, mesenteric lymph nodes (MLNs), Peyer's patches (PPs), $1 \mathrm{~cm}$ long duodenum segments and enteral flushing fluid were recovered to assess systematic and intestinal local immune response (Sun et al. 2019b).

\section{RT-PCR and IFT for detecting TsE mRNA and protein ex- pression in vivo}

TsE mRNA expression in spleen and MLNs of vaccinated mice was determined using RT-PCR at two weeks after the final vaccination. Total RNAs were extracted from spleens and MLNs with Trizol regents (Invitrogen, Carlsbad, USA). Mouse $\beta$-actin was also amplified as an internal control (Liu et al. 2014). PCR products were analysed on 1\% agarose gels (Wang et al. 2013). To investigate the TsE protein expression, $3 \mu \mathrm{m}$ tissue sections of spleen and MLNs of vaccinated mice were prepared. The sections were fixed with acetone and blocked with $5 \%$ normal goat serum at $37^{\circ} \mathrm{C}$ for one hour. Following washes with $\mathrm{PBS}$, the sections were probed with anti-rTsE serum ( $1: 10$ in PBS) at $4{ }^{\circ} \mathrm{C}$ overnight. After washes with PBS again, they were stained using FITC-conjugated anti-mouse $\operatorname{IgG}(1: 100)$, and observed in fluorescence microscope (Olympus, Japan) (Song et al. 2018b, Sun et al. 2018a). 


\section{Determination of anti-TsE antibodies}

Anti-rTsE antibodies (total IgG, IgG1, IgG2a and IgA) in serum samples of vaccinated mice were measured using indirect ELISA (Cui et al. 2015, Sun et al. 2015). In brief, the ELISA plate was coated with $1 \mu \mathrm{g} / \mathrm{ml} \mathrm{rTsE}$ for total IgG and $2 \mu \mathrm{g} / \mathrm{ml} \mathrm{rTsE} \mathrm{for} \mathrm{IgG1,}$ IgG2a and $\operatorname{IgA}$ overnight at $4{ }^{\circ} \mathrm{C}$. Blockage was performed with $5 \%$ nonfat milk at $37{ }^{\circ} \mathrm{C}$ for one hour. After washes with PBST, the plates were incubated at $37^{\circ} \mathrm{C}$ for $2 \mathrm{~h}$ with various dilute serum samples $(1: 100$ for detecting $\operatorname{IgG}, 1: 50$ for detecting $\operatorname{IgG} 1$, $\operatorname{IgG} 2 \mathrm{a}$ and $\operatorname{IgA})$, followed by incubation with HRP-conjugated anti-mouse $\operatorname{IgG}(1: 10,000), \operatorname{IgG} 1, \operatorname{IgG} 2 \mathrm{a}$ and $\operatorname{IgA}(1: 5000$; Sigma-Aldrich Co.) for one hour at $37^{\circ} \mathrm{C}$ (Sun et al. 2019a). Colouration was performed using OPD (Sigma-Aldrich Co.) plus $0.15 \%$ $\mathrm{H}_{2} \mathrm{O}_{2}$, and reaction was finished by the addition of $2 \mathrm{M} \mathrm{H}_{2} \mathrm{SO}_{4}$. The absorbance at $492 \mathrm{~nm}$ was measured by a microplate reader (Tecan, Schweiz, Switzerland) (Li et al. 2015, Liu et al. 2015d).

\section{Recognition of natural TsE at various stages of Trichinella spiralis by IFT}

The recognition of natural TsE at diverse life cycle stages of T. spiralis was investigated using IFT with $3 \mu \mathrm{m}$ thick cross-sections of worms as reported (Pompa-Mera et al. 2014, Qi et al. $2018 \mathrm{~b}$ ). The blockage was performed using 5\% normal goat serum at $37^{\circ} \mathrm{C}$ for one hour. After washing with PBS, the sections were incubated with various immune serum (1:10 dilution) at $37^{\circ} \mathrm{C}$ for one hour, stained using FITC-labelled anti-mouse IgG (1 : 100; Santa Cruz, USA), and observed under fluorescence microscope (Olympus, Japan) (Xu et al. 2020).

\section{Assay of enteral mucosal secretory IgA (sIgA) response}

To evaluate enteral local mucosal sIgA response on vaccination with pcDNA3.1-TsE, total and TsE-specific secretory sIgA in enteral fluid were determined (Liu et al. 2015b, Bermúdez-Cruz et al. 2016). In brief, a $20 \mathrm{~cm}$ long pieces of the small intestine was incised, and content was flushed by $1 \mathrm{ml}$ of cold PBS containing $1 \%$ protease inhibitor (Sangon Biotech, China). The eluting fluid was recovered, centrifuged at $10000 \mathrm{~g}$ for $5 \mathrm{~min}$, and supernatants were collected ( $\mathrm{Li}$ et al. 2018). Total SIgA was measured by a sandwich ELISA (Abcam, Cambridge, UK), and TsE-specific sIgA was determined by a conventional ELISA with $2 \mu \mathrm{g} /$ $\mathrm{ml}$ of rTsE as reported (Sun et al. 2015). Colouration with OPD and determination of absorbance at $492 \mathrm{~nm}$ were performed as described before (Liu et al. 2013, Ren et al. 2018).

\section{Investigation of enteral goblet cells/mucins}

One centimetre of the duodenum of vaccinated mouse was cut off at two weeks after the last vaccination. The duodenum was fixed using paraformaldehyde, embedded in paraffin, and cut into 3- $\mu \mathrm{m}$ thick sections (Long et al. 2015). To identify the generation of enteral mucus, sections were stained with alcian blue-periodic acid Schiff reagent (AB-PAS, Baso, China) (Sun et al. 2019b) Briefly, the section was dyed by alcian blue at $37^{\circ} \mathrm{C}$ for $15 \mathrm{~min}$. Following washes with PBS, the sections were oxidated with periodic acid for 10 mines, reacted with Schiff reagent at $37^{\circ} \mathrm{C}$ for $10 \mathrm{~min}$, and stained using hematoxylin. The goblet cells/mucins were examined under light microscopy, and goblet cells per intact intestinal villus were numbered.

\section{Determination of cytokine response}

To analyse cellular immune responses to pcDNA3.1/TsE vaccination, four cytokines (IL-2, IL-4, IL-10 and IFN- $\gamma$ ) from spleen, MLN and PP from vaccinated mice were measured at weeks $0,4,6$ and 8 after vaccination. Spleen, MLNs and PPs were homogenised using complete RPMI-1640 medium (Gibco, Auckland, New Zealand), the pellets were obtained after being centrifuged at $300 \mathrm{~g}$ for $5 \mathrm{~min}$, and the cells were harvested (Dea-Ayuela et al. 2006). These cells $\left(2 \times 10^{6} \mathrm{cells} / \mathrm{ml}\right)$ were stimulated using $10 \mu \mathrm{g} / \mathrm{ml}$ of rTsE at $37^{\circ} \mathrm{C}$ for $72 \mathrm{~h}$, supernatant was collected and the cytokine concentration $(\mathrm{pg} / \mathrm{ml})$ was measured using sandwich ELISA (Cui et al. 2013b).

\section{Challenge infection and evaluation of immune protection}

To determine the immune protective efficacy generated from pcDNA3.1/TsE vaccination, all vaccinated mice were challenged orally with 300 T. spiralis ML two weeks after the third vaccination. Ten mice from each group were euthanised at $7 \mathrm{dpi}$, adult worms were collected from the intestines and counted (Zhang et al. 2016). The remaining ten mice from each group were sacrificed at $42 \mathrm{dpi}$, each carcass was weighted, digested and the ML were collected and numbered as reported (Wang et al. 2015, Yang et al. 2019). The immune protective efficacy was ascertained as parasite burden reduction of intestinal AWs and larvae per gram (LPG) of muscles from of pcDNA3.1-TsE vaccinated mice relative to that of PBS group (Xu et al. 2017).

\section{Statistical analysis}

Statistical analysis was performed with SPSS for Windows, version 20.0. The data were shown as mean \pm standard deviation (SD). Difference among various groups was analysed by one-way ANOVA. $P<0.05$ was regarded as a statistical significance.

\section{RESULTS}

Identification of recombinant plasmid pcDNA3.1-TsE

Recombinant plasmid pcDNA3.1-TsE was digested using BamHI/XhoI. Electrophoresis of digestion products revealed that recombinant plasmid with an insert of about $1,350 \mathrm{bp}$ was successfully constructed. Sequence analysis demonstrated that the amplified TsE gene fragment consisting of $1,350 \mathrm{bp}$ was correctly cloned into the pcDNA3.1 (Fig. 1), and had $99.81 \%$ identity to the TsE sequence in GenBank (XP_003377838.1).

\section{The in vitro TsE mRNA and protein expression}

The in vitro TsE mRNA expression in BHK-21 cells was determined using RT-PCR. The results showed that amplified TsE fragments were detected in the cells transfected by pcDNA3.1/TsE, but not in the empty pcDNA3.1-transfected cells. TsE protein expression in the BHK-21 cells was examined by IFT with anti-TsE serum. Positive green fluorescence in pcDNA3.1/TsE transfected cells was observed by using anti-TsE serum and infection serum, but not in pcDNA3.1 transfected control cells (Fig. 2). 


\section{Bam HI Kozak}

GGATCCGCCACCATGATCCTTTTCAAGTGCTTATTTCTCCTTGCATATATAACGCAAGCT TTTGCCAATTATGAATGTGGCACCCTACCATCCACTTTTCCAAAAAGCGTTAAAGGAAA CAGAATTTCAGGAGGCTCTGTTGCAACACCAAATTCTATACCATATCAAGCAAGATTGG TCTTGGAAAAAGATGGTAATAGAATAAAACTATGCGGAGGTACTCTTGTAGAATTGAAA CCTGGAAATGGGAGTCAGTGGGTACTGACCGCAGCACATTGCACCTACTATGCAGATT TTGATAACACATTCAACTATATTGATAAATTTTATATCAGATATAGGAGAAATTTTGCCCC AGATAAAGTAGAGGTTATTCTTGGTGCCCACAGACCTAATGAAAAAGAAAGCACTCAA CATACAGTAGGCGCAAAGCGCATAATTAGCCATCCGCGTTACGATGATGTAGCAACAGT TTATGACCTCTCTCTAGTGCTTCTTAAAGAATATGTAATTTACAACAATGAAATTCGATC AGCATGCCTGCCTAAAGCGAATGAGCCAGTTCCATTGGATGTGCCATGCTTTGCAAGC GGATGGGGATTAACATATCGTACGTTAATGAAATCAACGTATTCAAAAAGCAATAATTTA ATAAATGCTGTATTAATAGACGGTGGACGTGGTTCGGAGGTTCTGAAAATTGCAGAAAT GAAAATATTACCAAAAGATGAATGTAGAATTAAACCAGAAGAGCATGCAATAGTTTTCT GTGCATTTGGTGTTGACCGCTCTGCAACATGCCAGGGCGACTCTGGTGGACCATTAGT GTGTTTGATAAACAACAAAGCAACATTGTACGGAATAGTCAGTTTTGGTCCGCCTATGT GCGGAGATGCAAGACACTCCGTAAAATTTGCTAAAGTCCCGGCAATGTTGGAATGGGT ACAAGATACTGCCCGAAGCATTGACTCTACTGTGCCTGTTGTGTCTCGATTTGAACCCA AACCAAGTGTAACTCCTGGCAGTGTAGTTGTTGGACAGGAAGATATTATGAAAGATTTA CCGAAAATTCCCACCAGAGATAACGTGAAAGATACTCCCAATAATTACAAAGGATCTG ACGTATTCAATTTTATACATAGAGATAGTTTTCCTTCTGAATCAAAATTCCCTGATTTGGA GCAAATAATGTCAGATTTCATGTCGCCTGGCGCTGGAGGAATGAAAGGTGGAAGCTTT TTCAATTCTCCACGTGTTTTCATAGAAACGAAAACCGTTAACCGTCTACCTTCTGTATC AAGAAGTAGAAGTGATGTTGGTAGATTTGGTTTCAATGATCCATCATTCACCTTTTTCC GTTAACTCGAC Xhol

Fig. 1. The cloned TsE sequences of Trichinella spiralis (Owen, 1835). Restriction enzyme sites of Bam HI and XhoI are highlighted in turquoise and Kozak sequence in yellow.

\section{The in vivo TsE mRNA and protein expression}

Total RNAs were extracted from vaccinated mouse spleen and MLNs at two weeks after the final vaccination, TsE mRNA expression in the tissues was ascertained by RT-PCR. The results showed that TsE mRNA was expressed in spleen and MLNs from mice immunised with pcDNA3.1/TsE, but not from mice injected with only empty pcDNA3.1 or PBS alone (Fig. 3). The IFT results revealed that fluorescent staining was observed in spleen and MLN sections of TsE DNA vaccine group, but not in empty pcDNA3.1 or PBS group. Furthermore, when the immunised mouse spleen and MLN sections were incubated with pre-immune serum, no fluorescence staining was seen. The results demonstrated that TsE mRNA and protein were expressed in spleen and MLNs of pcDNA3.1/TsE immunised mice.

\section{Systemic TsE-specific antibody response elicited by vaccination with pcDNA3.1/TsE}

As shown in Fig. 4, specific anti-TsE antibodies (total $\mathrm{IgG}, \mathrm{IgG} 1$ and $\mathrm{IgG} 2 \mathrm{a})$ of pcDNA3.1/TsE vaccinated
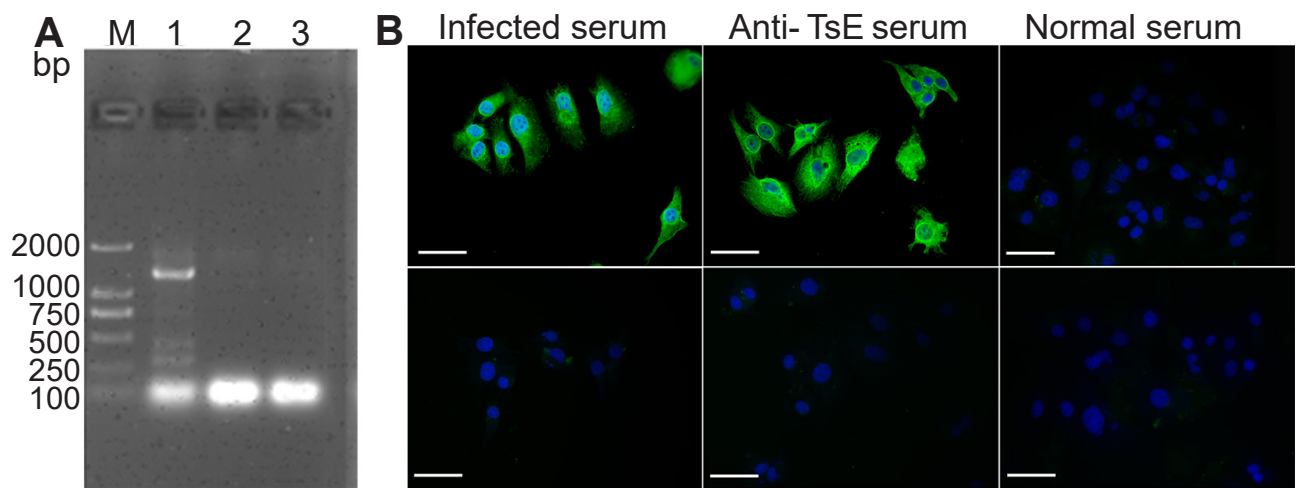

Fig. 2. The in vitro TsE expression in BHK-21 cells. A - the in vitro TsE mRNA expression in BHK-21 cells was determined by RTPCR; lane M - DNA marker; lane 1 - pcDNA3.1/TsE transfected cells; lane 2 - only pcDNA3.1 transfected cells; lane 3 - ddH ${ }_{2} \mathrm{O}$ control. B - TsE protein expression in BHK-21 cells was examined using immunofluorescence test with anti-rTsE serum. The expressed TsE protein in cells transfected with pcDNA3.1/TsE was probed by anti-TsE serum and infection serum, but not in pcDNA3.1 transfected control cells. Scale bar $=50 \mu \mathrm{m}$.
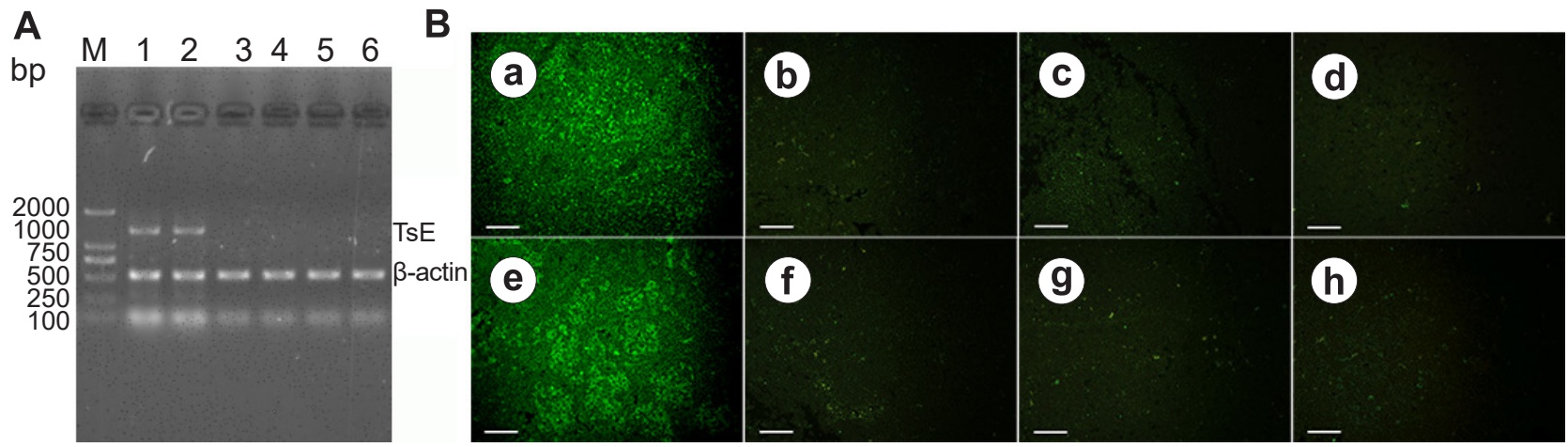

Fig. 3. The in vivo TsE mRNA and protein expression in spleen and mesenteric lymph nodes (MLNs) of immunised mice. A - TsE mRNA expression in spleen and MLNs of immunised mice were measured using RT-PCR. TsE amplified fragment was detected in spleen (lane 1) and MLNs (lane 2) from pcDNA3.1/TsE immunised mice, but neither in spleen (lane 3) and MLNs (lane 4) from empty pcDNA3.1 group, nor in spleen (lane 5) and MLNs (lane 6) from PBS group. B - IFT using anti-TsE serum reveals green fluorescence in immunised murine spleen (a) and MLN (e) sections, but not in spleen (b) and MLN (f) sections incubated with pre-immune serum. No green fluorescence in spleen (c) and MLNs (g) sections of only pcDNA3.1 inoculated mice was detected by anti-rTsE serum. Immuno-staining in spleen (c) and MLNs (g) sections of PBS-injected mice was not observed with anti-rTsE serum. Scale bar $=50 \mu \mathrm{m}$. 

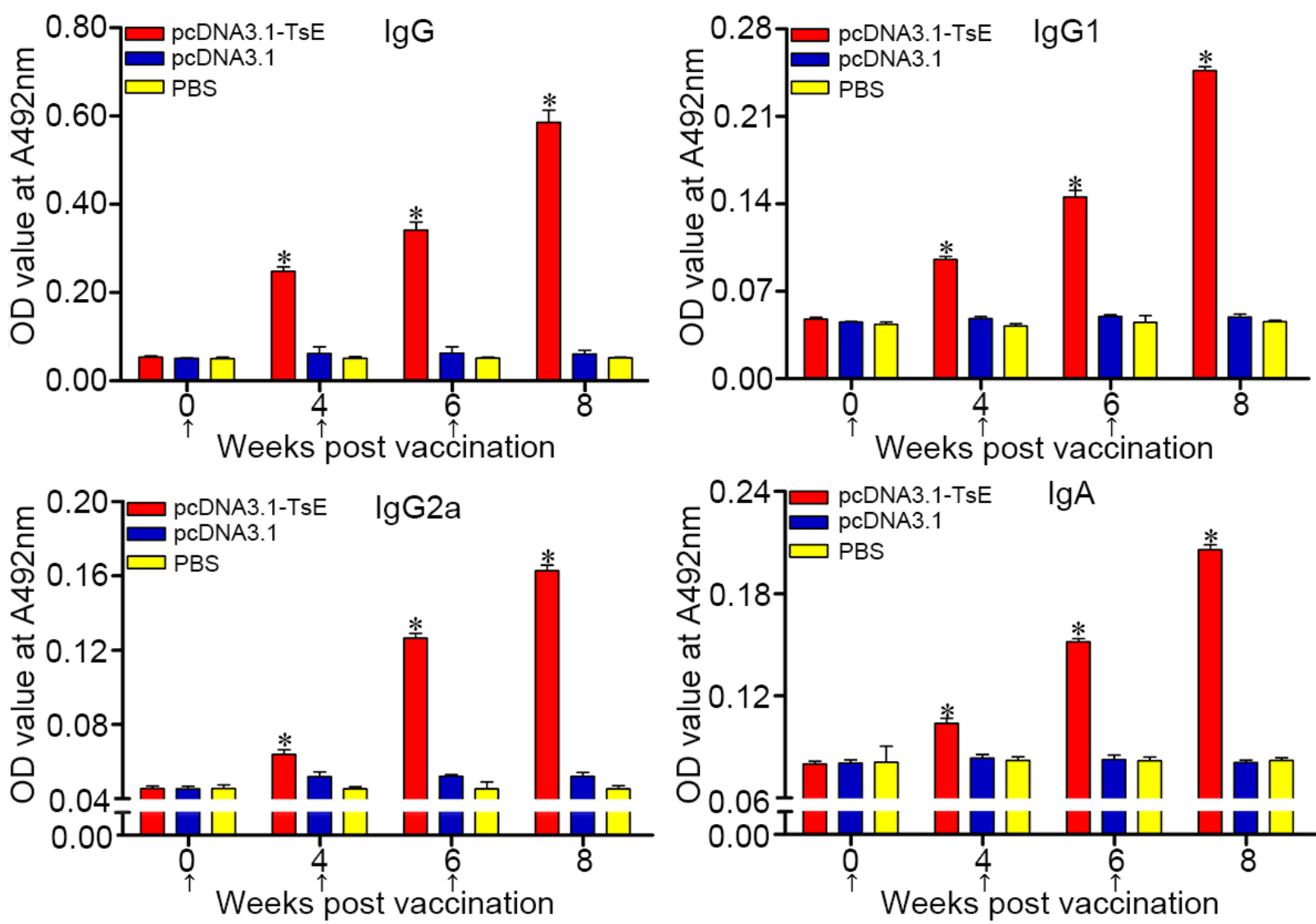

Fig. 4. Anti-TsE antibody response in mice vaccinated with pcDNA3.1/TsE, pcDNA3.1 or PBS. Specific anti-TsE antibodies (total $\mathrm{IgG}, \operatorname{IgG1}$ and $\operatorname{IgG} 2 \mathrm{a}$, and $\operatorname{IgA}$ ) were measured by ELISA at diverse time interval after vaccination. The OD values of each group were shown as mean \pm SD of antibody levels $(\mathrm{n}=10)$. Vaccination time point was signed with an arrows $(\uparrow) . * P<0.0001$ compared with empty pcDNA3.1 or PBS group.

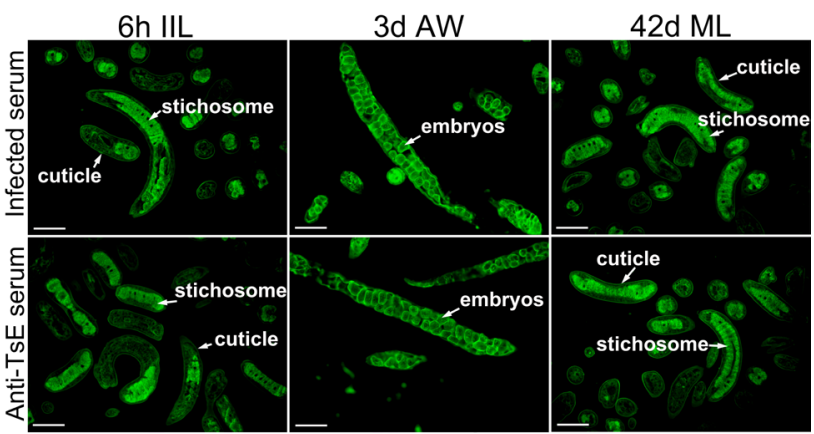

Fig. 5. Recognition of natural TsE at diverse stages of Trichinella spiralis visualised by immunofluorescence test with sera of mice vaccinated with pcDNA3.1/TsE, only pcDNA3.1 or PBS. Positive flurorence staining was located at cuticle, stichosome and around female embryos of this nematode. No worm tissues were recognised by sera from mice injected with empty pcDNA3.1 or PBS. Scale bar $=50 \mu \mathrm{m}$.

mice at 4, 6 and 8 weeks after vaccination were evidently higher than those of empty pcDNA3.1 and PBS groups $(P<0.0001)$, suggesting that a mixed Th1/Th2 immune response was triggered by pcDNA3.1-TsE vaccination. Moreover, TsE-specific IgA response was also elicited in the vaccinated mice.

\section{Recognition of natural TsE at various stages of Trichinella spiralis by IFT}

The IFT results indicated that natural TsE on cross-sections of IIL, adult worms and muscle larvae was recognised by anti-TsE serum from pcDNA3.1/TsE vaccinated mice. Immunostaining was principally located at the cuticle, stichosome and around female embryos of this parasite (Fig. 5). However, no worm tissues were identified by using serum from mice injected with empty pcDNA3.1 or PBS.

\section{Enteral local mucosal sIgA response}

To investigate local enteral mucosal $\operatorname{sIgA}$ response to pcDNA3.1/TsE vaccination, total and TsE-specific sIgA were assayed by ELISA. The results showed that total sIgA level in pcDNA3.1-TsE vaccinated mice was remarkably higher than those of only pcDNA3.1 or PBS group (Fig. 6A) $\left(F_{4 \mathrm{w}}=186.037, F_{6 \mathrm{w}}=478.646, F_{8 \mathrm{w}}=804.413\right.$, $P<0.0001)$. TsE-specific sIgA level in pcDNA3.1-TsE vaccinated mice was also significantly higher than those of empty pcDNA3.1 or PBS group (Fig. 6B) $\left(F_{4 \mathrm{w}}=126.359\right.$, $\left.F_{6 \mathrm{w}}=321.75, F_{8 \mathrm{w}}=360.426, P<0.0001\right)$. No TsE-specific sIgA response was observed in mice inoculated with empty pcDNA3.1 or PBS alone. 


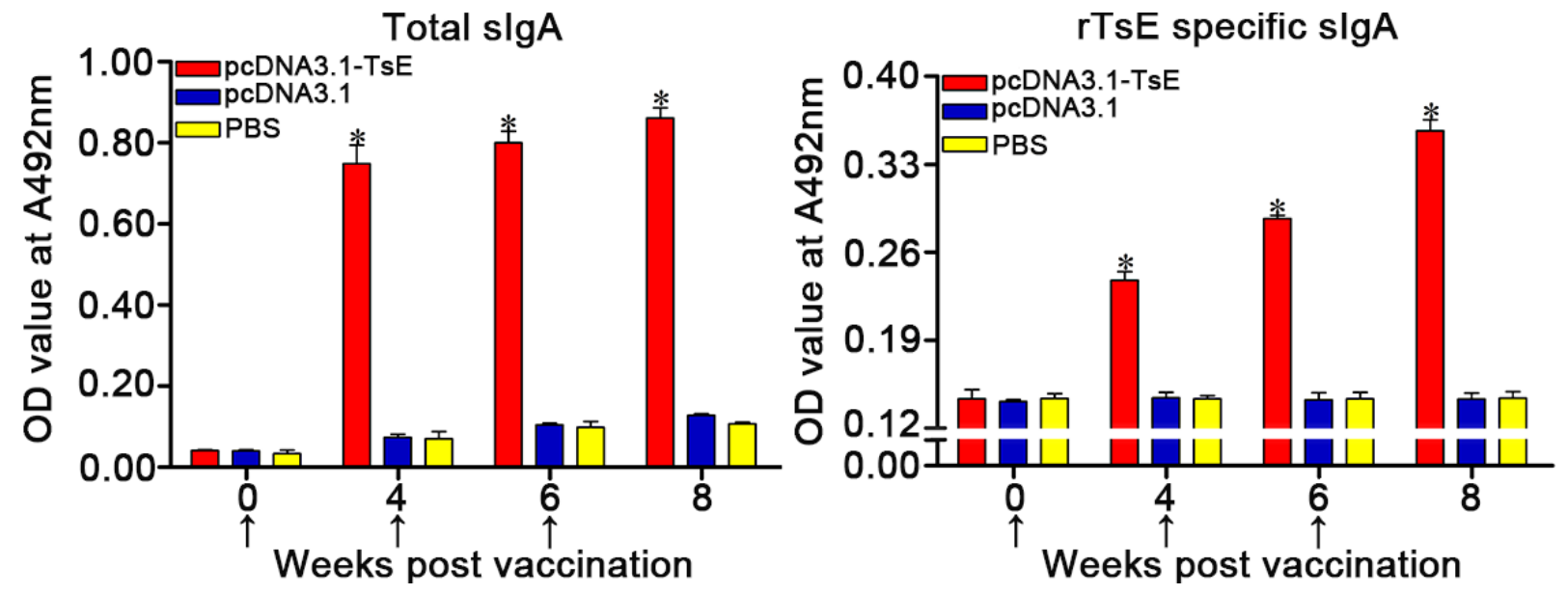

Fig. 6. Total enteral $\operatorname{sg} A(A)$ and TsE-specific $\operatorname{sg} A(B)$ in enteral flushing of pcDNA3.1-TsE vaccinated mice. The results were presented as mean OD values \pm SD of 10 animals per group. No obvious enteral sIgA response was detected in mice injected with only empty pcDNA3.1 or PBS. Vaccination time point was signed with an arrow $(\uparrow) .{ }^{*} P<0.0001$ compared with empty pcDNA3.1 or PBS group.

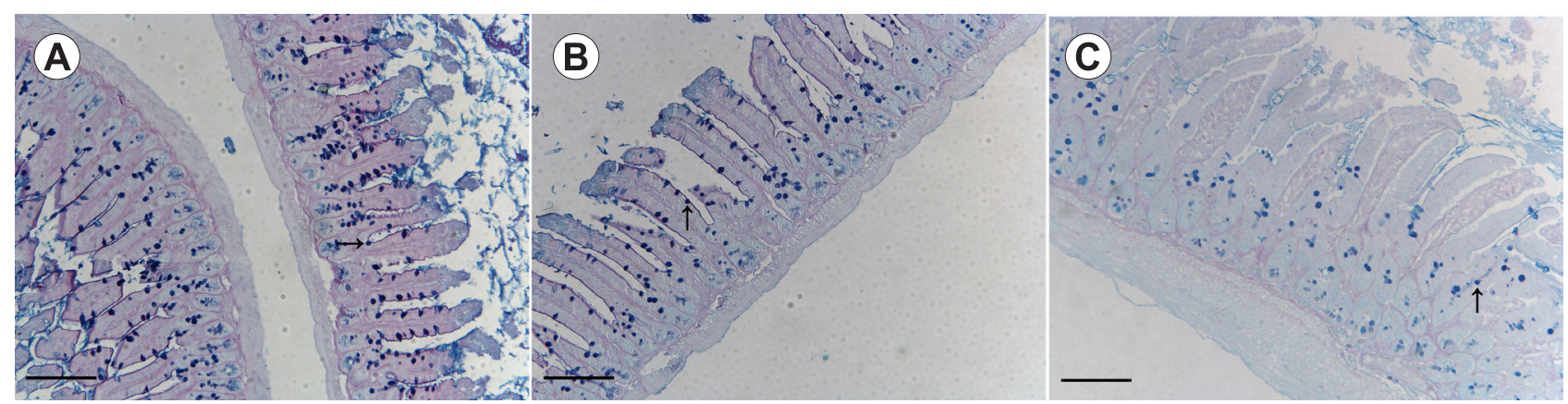

Fig. 7. A - AB-PAS staining of goblet cells/mucin in intestinal epithelia of mice vaccinated with pcDNA3.1/TsE; B - only pcDNA3.1; C - PBS. The duodenum was obtained at two weeks after last vaccination from each group, cut and dyed with AB-PAS. Acid mucin was dyed bluish violet.

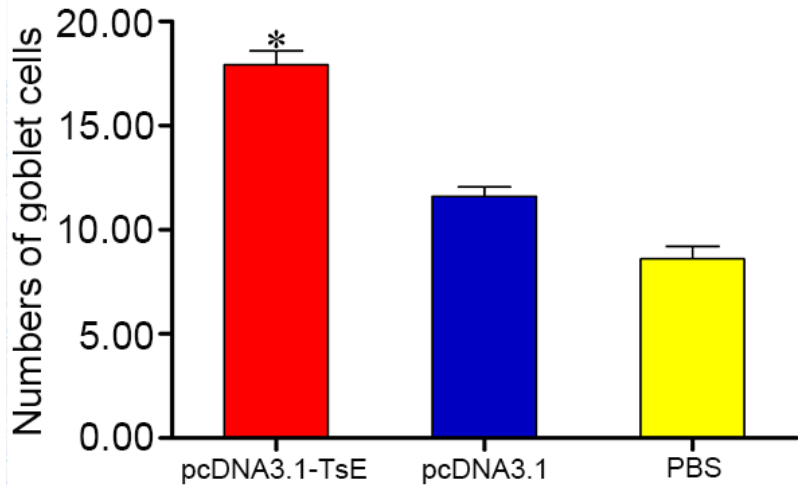

Fig. 8. Quantification of goblet cells/mucin per intestinal villus. Data show the mean $\pm \mathrm{SD}$ of three animals per group. Arrows show goblet cells/mucins. $* P<0.0001$ compared with pcDNA3.1 and PBS group.

\section{Enteral goblet cells/mucins}

The duodenum was obtained at two weeks after the last vaccination. Duodenal tissue section was dyed with ABPAS, a plentiful of acidic mucin was dyed bluish violet, and identified in enteral mucosa from pcDNA3.1-TsE vaccinated mice. A number of acidic mucin was also observed in empty pcDNA3.1 group. However, a little of mucin was detected in PBS group (Fig. 7). The amount of enteral goblet cells/mucins in pcDNA3.1/TsE vaccinated mice was obviously higher than that of empty pcDNA3.1 or PBS group (Figs. 7, 8) $(F=65.572, P<0.0001)$.

\section{Evaluation of cytokine response}

The results of cytokine assay revealed that the level of Th1 (IFN- $\gamma$, IL-2)/Th2 (IL-4, IL-10) cytokines at 4, 6 and 8 weeks after pcDNA3.1/TsE vaccination was significantly higher than those of only pcDNA3.1 or PBS injection $(P<$ 0.0001) (Fig. 9). The results indicated that pcDNA3.1-TsE vaccination elicited the concurrent $\mathrm{Th} 1 / \mathrm{Th} 2$ responses in the light of TsE-specific IgG subclass and cytokine response. It was also suggested that intramuscular inoculation of pcDNA3.1-TsE induced both systemic (spleen) and intestinal local (MLNs and PPs) cellular immune response.

Immune protective efficacy of pcDNA3.1/TsE vaccination

Compared to PBS blank control mice, the mice vaccinated with pcDNA3.1/TsE exhibited a 17\% intestinal AW reduction at 7 dpi (Fig. 10a) and a 39\% ML reduction at 42 dpi (Fig. 10b) after challenge with 300 Trichinella spiralis $\operatorname{ML}\left(F_{\mathrm{AW}}=50.302, P<0.01 ; F_{\mathrm{ML}}=8.925, P<0.0001\right)$. 

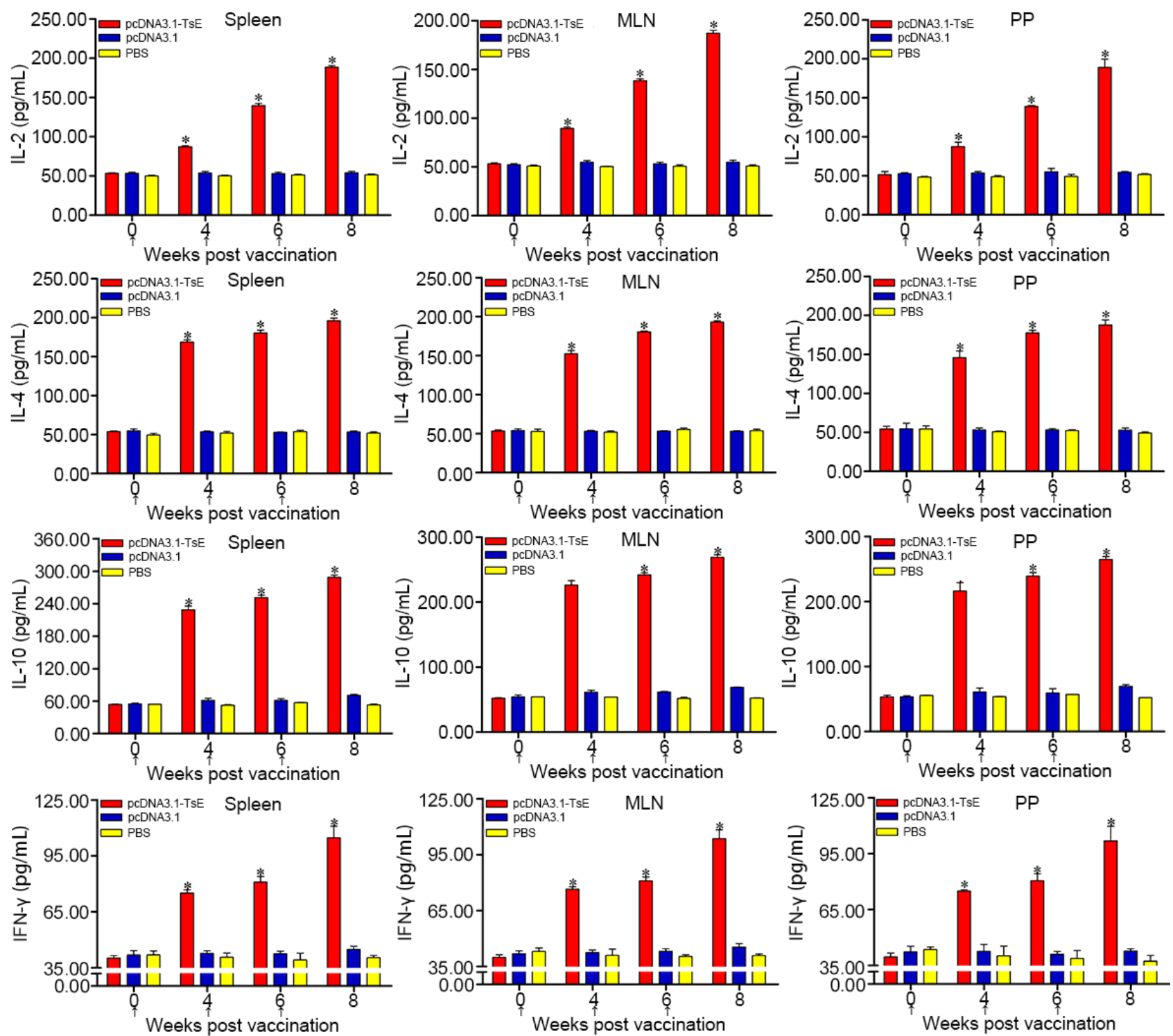

Fig. 9. ELISA determination of cytokines produced by spleen, mesenteric lymph nodes (MLNs) and Peyer's patches (PPs) from pcDNA3.1/TsE vaccinated mice at diverse times following vaccination. The concentration of cytokines (IL-2, IL-4, IL-10 and IFN- $\gamma$ ) was measured by ELISA after spleen, MLN and PP cells were stimulated with rTsE. The data are presented as mean \pm SD of ten animals per group. ${ }^{*} P<0.0001$ compared to empty pcDNA3.1 or PBS group.

\section{DISCUSSION}

Serine protease is a major protease family and plays an important role in protection against helminthoses. The protease can degrade different host proteins and enteral mucin, participates in the larval intrusion, growth and molting (Nagano et al. 2003, Yang et al. 2015b). Elastases belong to a trypsin-like serine protease which has the ability to hydrolyse various tissue components, such as fibronectin, laminin, collagen and elastin. The elastases are involved in the parasite invasion and digestion, and might a crucial role act in worm invasion (El-Faham et al. 2017). In a previous study, the TsE was cloned and expressed in Escherichia coli, and the rTsE might be a novel target molecule for anti-T. spiralis vaccines (Hu et al. 2020). Nevertheless, the proteins expressed in prokaryotic plasmids might differ from the natural active proteins on the basis of their structure and function (Liu et al. 2014).

The recombinant protein fold and post-translational modification (e.g., glycosylation) could be obtained in DNA vaccine with eukaryotic expression plasmid, and the surface-exposed recombinant antigenic epitopes would be also exhibited correctly like the native protein structures (Wang et al. 2016). The DNA vaccine is more attractive duo to its ability to induce a broad and lasting immune response (Liu et al. 2015a). An effective DNA vaccine usually requires to be administered more than one boost vaccination. Moreover, the DNA vaccine is commonly used through intramuscular injection (Wang et al. 2006, Xu et al. 2017).

In the present work, the complete $\mathrm{TsE}$ sequence was cloned into pcDNA3.1, and TsE mRNA and protein expres- 
A

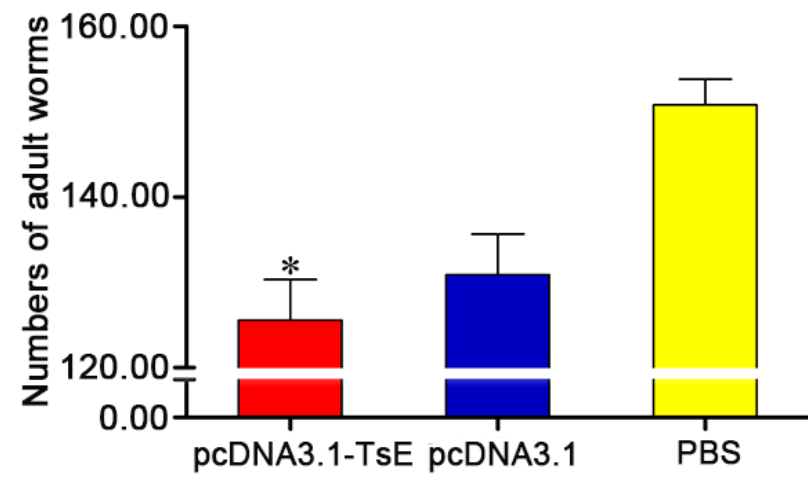

B

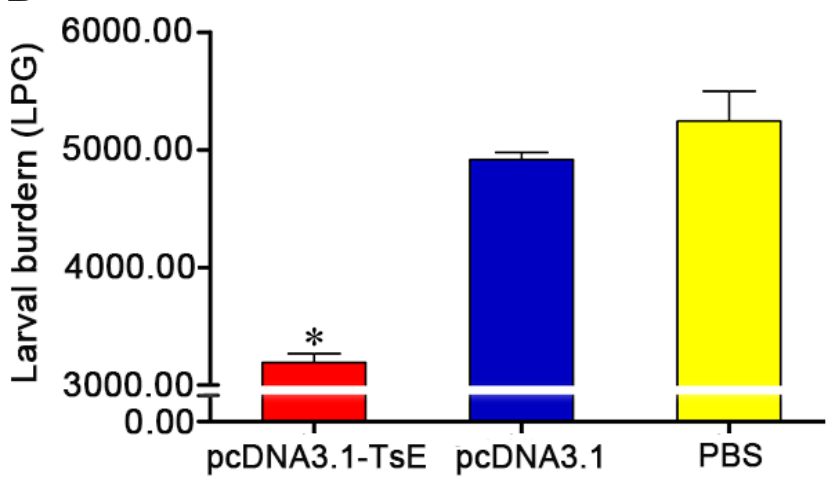

Fig. 10. Protective efficacy of pcDNA3.1/TsE vaccination after challenge with $300 \mathrm{~T}$. spiralis infective larvae of Trichinella spiralis in a murine model. A - Intestinal adult worm burden; B - Muscle larvae burden (larvae per gram, LPG). The parasite burden is shown as mean \pm SD from pcDNA3.1-TsE-vaccinated mice, empty pcDNA3.1 or PBS group $(\mathrm{n}=10)$. ${ }^{*} P<0.01$ compared with empty pcDNA3.1 or PBS group.

sion was observed in pcDNA3.1/TsE transfected- BHK-21 cells in vitro, suggesting that the TsE DNA vaccine was successfully prepared. The results of RT-PCR and IFT demonstrated that the TsE mRNA and protein were also expressed in spleen and MLNs of pcDNA3.1/TsE immunised mice. Cellular uptake of DNA is relatively inefficient following intramuscular injection, and therefore expression of the encoded antigen is low. Strong promoters have been shown to increase expression levels and the immediate/early promoter from cytomegalovirus (CMV) is the most effective and frequently used. Muscle-damaging agents, such as bupivacaine, have increased gene expression (Xu et al. 2017). In the present study, the pcDNA3.1 vaccine vector which contains the strong CMV promoter was used for the construction of TsE DNA vaccine and 5\% bupivacaine hydrochloride was injected into the quadriceps of mice three days before intramuscular vaccination. The results showed that the TsE protein expression in muscular and other cells of inoculated mice was detected. However, their transport mechanism within cells is still unknown.

Antibody assay demonstrated that intramuscular vaccination with TsE DNA triggered not only the systemic specific antibody response (IgG and subclass IgG1/IgG2a, and $\operatorname{IgA}$ ) and also enteral local mucosal sIgA responses. Anti-rTsE sera from vaccinated mice identified the natural TsE at the epicuticle, stichosome of IIL larvae and around female embryos of this nematode. Anti-Trichinella antibodies (mainly IgG) binding to the epicuticle of enteral invasive stage larvae (6 h IIL) of Trichinella spiralis might be involved in the partial blockage of larval intrusion of intestinal epithelia, because the antigen-antibody complex formation at the larval anterior end could physically separate the larval direct contact with intestinal epithelia and interrupt the larval penetration into the intestinal mucosa (McVay et al. 1998, Wang et al. 2013).

Additionally, the sIgA plays a vital role for mucosal barrier defense and prevents from parasite invasion into the enteral epithelia (Wang et al. 2006, Martinez-Gomez et al. 2009, Li et al. 2018). The T. spiralis-specific sIgA participated and accelerated the parasite expulsion from the in- testine. Passive immunisation of mice with anti-Trichinella antibody IgA exhibited an obvious immune protection against challenge infection (Inaba et al. 2003). The generation of mucosal sIgA is Th2-dependent; in particular, IL-10 is a main cytokine that enhances the $\operatorname{IgA}$ response (Pompa-Mera et al. 2014). In the present study, the correlation of high intestinal sIgA levels and high IL-10 levels demonstrate that cytokine IL-10 might enhance the intestinal mucosal sIgA response.

Our results also showed a plentiful of enteral mucosal goblet cells/mucins induced in pcDNA3.1-TsE vaccinated mice. Previous studies showed that the enteral stage of T. spiralis were trapped in intestinal mucus of immunised mice (Castillo Alvarez et al. 2013). The main function of enteral mucus is to play a physical barrier to protect intestinal epithelium. It can also cover the worm bodies and limits the worm activity (Hasnain et al. 2012, Sharpe et al. 2018, Sun et al. 2019b). The results also showed that vaccination with TsE DNA elicited the concomitant Th1/Th2 immunity, as shown by a clearly ascended level of Th1 cytokines (IFN- $\gamma$ and IL-2) and Th2 cytokines (IL-4 and IL10) following spleen, MLN and PP cells from vaccinated mice being stimulated by rTsE. The concomitant Th1/Th2 response is also important for immune protection against $T$. spiralis infection (Pompa-Mera et al. 2014).

After being challenged with $300 T$. spiralis ML, the mice vaccinated with pcDNA3.1/TsE showed a $17 \%$ intestinal AW reduction at $7 \mathrm{dpi}$ and a $39 \%$ ML reduction at 42 . The worm burden reduction observed in this work is similar to those of intramuscular vaccination with DNA vaccines of $T$. spiralis enolase, Ts45 protein and a T. spiralis multicystatin-like domain protein (TsMCD-1) (Tang et al. 2012, Zhang et al. 2018b), but it was lower than the protective efficacy of DNA vaccines of $T$. spiralis nudix hydrolase (54\% larval reduction) (Liu et al. 2015a) and newborn larval serine protease-like protein (78\%) (Xu et al. 2017). The significant difference between adult and larval burden observed in this study is likely because the TsE DNA vaccine might have an obvious inhibitory effect on the female fecundity and newborn larvae. Previous stud- 
ies indicated that intestinal sIgA inhibited the female adult reproductive capacity of $T$. spiralis (Liu et al. 2015a). Additionally, anti-Trichinella antibodies also participated in killing of newborn larvae through an ADCC mode (Song et al. 2018a, Zhang et al. 2020). Hence, although the adult worm reduction in the intestine of mice vaccinated with pcDNA3.1/TsE is low, larval burden reduction in muscle of vaccinated mice is more evident.

Trichinella spiralis is a multicellular parasitic nematode, it has the diverse life-cycle stages (muscle larvae, adult worms and newborn larvae), and transient intestinal and migratory stages (intestinal infective L1-L4 larvae, migratory larvae and pre-encapsulated larvae) (Despommier 1983). During natural T. spiralis infection, each life-cycle stage has its stage-specific antigens (Parkhouse and Ortega-Pierres 1984, Ren et al. 2019). Vaccination of animals with an individual $T$. spiralis protein molecule only induced a partial protection following challenge infection. The DNA vaccines containing multiple antigenic molecules (or immune costimulatory molecules, such as macrophage migration inhibitory factor, murine CR2 binding domain of $\mathrm{C} 3 \mathrm{~d}$ and $\mathrm{Th} 2$ cytokines) have significantly improved the immune protection (Pompa-Mera et al. 2014).

To prevent and control $T$. spiralis infection, the vaccination with preventive anti-Trichinella vaccines should interrupt the IIL larval penetration into the intestinal mucosa, to block the IIL larval development to adulthood, to expel the adults from intestine, to impede the NBL generation and kill NBL (Ortega-Pierres et al. 2015). Additionally, Trichinella infection is acquired mainly from the oral ingestion of infected meat. Therefore, the oral polyvalent anti-Trichinella vaccines should be developed. These vaccines should include multiple epitopes from different $T$. spiralis life-cycle stages (Gu et al. 2020, Qi et al. 2018a).

Vaccination of mice with attenuated Salmonella expressing a T. spiralis gp43 antigen-derived 30-mer peptide fused to the molecular adjuvant C3d-P28 produced a 93\% reduction of enteral AW burden after challenge (Pompa-Mera et al. 2014). When the mixed plasmid of pVAX1Ts43 and pVAX1-Ts45 were used to vaccinate the mice, their larval reduction (52 and 34\%) was increased to $76 \%$ (Wang et al, 2018).

The multiple epitope vaccines (MEP) have been studied in several parasite infections. In lymphatic filariasis, thioredoxin-transglutaminase MEP produced a significantly higher protection of $63 \%$ than the whole protein cocktail vaccine (56\%) in a model of jird (Immanuel et al. 2017). This multiple antigenic epitope vaccine has strong immunogenicity and could enhance the protective immune response in vaccinated animals. Screening and identification of these antigenic epitopes are a crucial for the design of a multiple epitope vaccine. The immunogenic epitopes of the proteins might be screened and identified by epitope prediction algorithms with bioinformatics or by corresponding antibodies. These epitopes should be verified for their capacity to trigger strong and long-lasting humoral and cellular immune responses against the infection $(\mathrm{Gu}$ et al. 2020).

In conclusion, the results of the present work indicated that intramuscular vaccination of mice with pcDNA3.1/ TsE induced a systemic concomitant Th1/Th2 immune response and a local intestinal mucosal sIgA response. The immune responses elicited by vaccination with TsE DNA vaccine produced a partial protection against $T$. spiralis challenge infection. The oral polyvalent vaccine including multiple epitopes from various life-cycle stages of T. spiralis should be developed to improve the protective efficacy of anti-Trichinella vaccines.

Acknowledgements. This study was supported by grants of the National Natural Science Foundation of China (81971952 and U1704284).

\section{REFERENCES}

Bermúdez-Cruz R.M., Fonseca-Liñán R., Grijalva-Contreras L.E., Mendoza-Hernández G., Ortega-Pierres M.G. 2016: Proteomic analysis and immunodetection of antigens from early developmental stages of Trichinella spiralis. Vet. Parasitol. 231: 223-231.

Castillo Alvarez A.M., Vaquero-Vera A., Fonseca-Liñán R., Ruiz-Pérez F., Villegas-Sepúlveda N., OrteGA-Pierres G. 2013: A prime-boost vaccination of mice with attenuated Salmonella expressing a 30-mer peptide from the Trichinella spiralis gp43 antigen. Vet. Parasitol. 194: 202-206.

Cui J., Han Y., Yue X., Liu F., Song. Y.Y., Yan S.W., Lei J.J., ZHANG X., JiANG P., WANG Z.Q. 2019: Vaccination of mice with a recombinant novel cathepsin B inhibits Trichinella spiralis development, reduces the fecundity and worm burden. Parasit. Vectors 12: 581.

Cui J., JiAng P., Liu L.N., WANG Z.Q. 2013a: Survey of Trichinella infections in domestic pigs from northern and eastern Henan, China. Vet. Parasitol. 194: 133-135.

Cui J., Ren H.J., Liu R.D., Wang L., Zhang Z.F., Wang Z.Q. 2013b: Phage-displayed specific polypeptide antigens induce significant protective immunity against Trichinella spiralis infection in BALB/c mice. Vaccine 31: 1171-1177.
Cui J., Wang L., Sun G.G., Liu L.N., Zhang S.B., Liu R.D., Xi Z., JiAng P., WANG Z.Q. 2015: Characterization of a Trichinella spiralis $31 \mathrm{kDa}$ protein and its potential application for the serodiagnosis of trichinellosis. Acta Trop. 142: 57-63

Cui J., Wang Z.Q., Xu B.L. 2011: The epidemiology of human trichinellosis in China during 2004-2009. Acta Trop. 118: 1-5.

Cui J., Wang Z.Q. 2011: An epidemiological overview of swine trichinellosis in China. Vet. J. 190: 324-328.

Dea-Ayuela M.A., Rama-IÑiguez S., Bolas-Fernández F. 2006: Vaccination of mice against intestinal Trichinella spiralis infections by oral administration of antigens microencapsulated in methacrilic acid copolymers. Vaccine 24: 2772-2780.

Despommier D.D. 1983: Biology. In: W. Campbell (Ed.), Trichinel$l a$ and Trichinosis. Plenum Press, New York, pp. 75-151

El-Faham M.H., Wheatcroft-Francklow K.J., Price H.P., SAyers J.R., Doenhoff M.J. 2017: Schistosoma mansoni cercarial elastase (SmCE): differences in immunogenic properties of native and recombinant forms. Parasitology 144: 1356-1364.

Feidas H., Kouam M.K., Kantzour V., Theodoropoulos G. 2014: Global geographic distribution of Trichinella species and genotypes. Infect. Genet. Evol. 26: 255-266. 
Gu Y., Sun X., Huang J., Zhan B., Zhu P. 2020: A multiple antigen peptide vaccine containing CD4+T cell epitopes enhances humoral immunity against Trichinella spiralis infection in mice. J. Immunol. Res. 2020: 2074803.

Hasnain S.Z., McGuckin M.A., Grencis R.K., Thornton D.J. 2012: Serine protease(s) secreted by the nematode Trichuris muris degrade the mucus barrier. PLoS Negl. Trop. Dis. 6: e1856.

Hu C.X., Jiang P., Yue X., Zeng J., Zhang X.Z., Song Y.Y., LiU R.D., Zhang X., WANG Z.Q., Cui J. 2020: Molecular characterization of a Trichinella spiralis elastase-1 and its potential as a diagnostic antigen for trichinellosis. Parasit. Vectors 13: 97.

Immanuel C., Ramanathan A., Balasubramaniyan M. Khatri V.K., Amdare N.P., Rao D.N., Reddy M.V.R., Perumal K. 2017: Immunoprophylaxis of multi-antigen peptide (MAP) vaccine for human lymphatic filariasis. Immunol. Res. 65: 729738.

Inaba T., Sato H., Kamiya H. 2003: Monoclonal IgA antibody-mediated expulsion of Trichinella from the intestine of mice. Parasitology 126: 591-598.

Jiang P., Wang Z.Q., Cui J., Zhang X. 2012: Comparison of artificial digestion and Baermann's methods for detection of Trichinella spiralis pre-encapsulated larvae in muscles with low-level infections. Foodborne Pathog. Dis. 9: 27-31.

Jiang P., Zhang X., Wang L.A., Han L.H., Yang M., Duan J.Y., Sun G.G., Qi X., Liu R.D., WANG Z.Q., CuI J. 2016: Survey of Trichinella infection from domestic pigs in the historical endemic areas of Henan province, central China. Parasitol. Res. 115: 4707-4709.

Li J.F., Guo K.X., Qi X., Lei J.J., Han Y., Yan S.W., Jiang P., Yu C., Cheng X.C., Wang Z.Q., Cui J. 2018: Protective immunity against Trichinella spiralis in mice elicited by oral vaccination with attenuated Salmonella-delivered TsSP1.2 DNA. Vet. Res. 49: 87.

Li L.G., Wang Z.Q., Liu R.D., Yang X., Liu L.N., Sun G.G., Jiang P., Zhang X., Zhang G.Y., Cui J. 2015: Trichinella spiralis: low vaccine potential of glutathione $\mathrm{S}$-transferaseagainst infections in mice. Acta Trop. 146: 25-32.

Liu C.Y., Ren H.N., Song Y.Y., Sun G.G., Liu R.D., Jiang P., Long S.R., Zhang X., Wang Z.Q., Cui J. 2018: Characterization of a putative glutathione S-transferase from the parasitic nematode Trichinella spiralis. Exp. Parasitol. 187: 59-66.

Liu C.Y., Song Y.Y., Ren H.N., Sun G.G., Liu R.D., Jiang P., Long S.R., Zhang X., Wang Z.Q., Cui J. 2017: Cloning and expression of a Trichinella spiralis putative glutathione S-transferase and its elicited protective immunity against challenge infections. Parasit. Vectors 10: 448.

LiU L.N., Jing F.J., CUi J., Fu G.Y., Wang Z.Q. 2013: Detection of circulating antigen in serum of mice infected with Trichinella spiralis by an IgY-IgM mAb sandwich ELISA. Exp. Parasitol. 133: $150-155$.

Liu L.N., Wang Z.Q., Zhang X., Jiang P., Qi X., Liu R.D., Zhang Z.F., CUi J. 2015d: Characterization of Spirometra erinaceieuropaei plerocercoid cysteine protease and potential application for serodiagnosis of sparganosis. PLoS Negl. Trop. Dis. 9: e0003807.

Liu P., Cui J., Liu R.D., Wang M., Jiang P., Liu L.N., Long S.R., Li L.G., Zhang S.B., Wang Z.Q. 2015a: Protective immunity against Trichinella spiralis infection induced by TsNd vaccine in mice. Parasit. Vectors 8: 185.

LiU P., Wang Z.Q., Liu R.D., Jiang P., Long S.R., LiU L.N., Zhang X.Z., Cheng X.C., Yu C., Ren H.J., Cui J. 2015b: Oral vaccination of mice with Trichinella spiralis nudix hydrolase DNA vaccine delivered by attenuated Salmonella elicited protective immunity. Exp. Parasitol. 153: 29-38.

Liu R.D., Cui J., Liu X.L., Jiang P., Sun G.G., Zhang X., Long S.R., WANG L., Wang Z.Q. 2015c: Comparative proteomic analysis of surface proteins of Trichinella spiralis muscle larvae and intestinal infective larvae. Acta Trop. 150: 79-86.
LiU X.D., Wang X.L., Bai X., LiU X.L., Wu X.P., Zhao Y., Sun S.M., Yu L., Su X.Z., Wang Z.Q., Wang F., Liu M.Y., 2014: Oral administration with attenuated Salmonella encoding a Trichinella cystatin-like protein elicited host immunity. Exp. Parasitol. 141: 1-11.

Long S.R., Wang Z.Q., Jiang P., Liu R.D., Qi X., Liu P., Ren H.N., SHi H.N., CUi J. 2015: Characterization and functional analysis of Trichinella spiralis Nudix hydrolase. Exp. Parasitol. 159: 264-273.

Long S.R., Wang Z.Q., Liu R.D., Liu L.N., Li L.G., Jiang P., Zhang X., Zhang Z.F., Shi H.N., Cui J. 2014: Molecular identification of Trichinella spiralis nudix hydrolase and its induced protective immunity against trichinellosis in BALB/c mice. Parasit. Vectors 7: 600

Martinez-Gomez F., Santiago-Rosales R., Ramon B.C. 2009: Effect of Lactobacillus casei Shirota strain intraperitoneal administration in CD1 mice on the establishment of Trichinella spiralis adult worms and on IgA anti-T. spiralis production. Vet. Parasitol. 162: 171-175.

Mitreva M., Jasmer D.P., Zarlenga D.S., Wang Z., Abubucker S., Martin J., Taylor C.M., Yin Y., Fulton L., Minx P., Yang S.P., Warren W.C., Fulton R.S., Bhonagiri V., Zhang X., Hallsworth-Pepin K., Clifton S.W., McCarter J.P., Appleton J., Mardis E.R., Wilson R.K. 2011: The draft genome of the parasitic nematode Trichinella spiralis. Nat. Genet. 43: 228-235.

Nagano I., Wu Z., Nakada T., Boonmars T., Takahashi Y. 2003: Molecular cloning and characterization of a serine proteinase gene of Trichinella spiralis. J. Parasitol. 89: 92-98.

Ortega-Pierres G., Vaquero-Vera A., Fonseca-Linan R., Bermudez-Cruz R.M., Arguello-Garcia R. 2015: Induction of protection in murine experimental models against Trichinella spiralis: an up-to-date review. J. Helminthol. 89: 526-539.

Parkhouse R.M., Ortega-Pierres G. 1984: Stage-specific antigens of Trichinella spiralis. Parasitology 88: 623-630.

Pompa-Mera E.N., Arroyo-Matus P., Ocana-Mondragon A., Gonzalez-Bonilla C.R., Yepez-Mulia L. 2014: Protective immunity against enteral stages of Trichinella spiralis elicited in mice by live attenuated Salmonella vaccine that secretes a 30-mer parasite epitope fused to the molecular adjuvant C3d-P28. Res. Vet. Sci. 97: 533-545.

Pozıo E. 2007: World distribution of Trichinella spp. infections in animals and humans. Vet. Parasitol. 149: 3-21.

Qi X., Han Y., Jiang P., Yue X., Ren H.N., Sun G.G., Long S.R., Yu C., Cheng X.C., CuI J., Wang Z.Q. 2018a: Oral vaccination with Trichinella spiralis DNase II DNA vaccine delivered by attenuated Salmonella induces a protective immunity in BALB/c mice. Vet. Res. 49, 119.

Qi X., Yue X., Han Y., Jiang. P., Yang F., Lei J.J., Liu R.D., Zhang X., WANG Z.Q., CUI J. 2018b: Characterization of two Trichinella spiralis adult-specific DNase II and their capacity to induce protective immunity. Front. Microbiol. 9, 2504.

Ren H.N., Guo K.X., Zhang Y., Sun G.G., Liu R.D., Jiang P., Zhang X., Wang L., Cui J., Wang Z.Q. 2018: Molecular characterization of a $31 \mathrm{kDa}$ protein from Trichinella spiralis and its induced immune protection in BALB/c mice. Parasit. Vectors 11: 625 .

Ren H.N., Liu R.D., Song Y.Y., Zhuo T.X., Guo K.X., Zhang Y., JiANG P., WANG Z.Q., CUI J. 2019: Label-free quantitative proteomic analysis of molting-related proteins of Trichinella spiralis intestinal infective larvae. Vet. Res. 50: 70.

Rostami A., Gamble H.R., Dupouy-Camet J., Khazan H., BRUSCHI F. 2017: Meat sources of infection for outbreaks of human trichinellosis. Food Microbiol. 64: 65-71.

Sharpe C., Thornton D.J., Grencis R.K. 2018: A sticky end for gastrointestinal helminths; the role of the mucus barrier. Parasite Immunol. 40: e12517.

Song Y.Y., Wang L.A., Ren H.N., Qi X., Sun G.G., Liu R.D., Jiang P., Zhang X., Cui J., Wang Z.Q. 2018a: Cloning, ex- 
pression and characterisation of a cysteine protease from Trichinella spiralis. Folia Parasitol. 65: 007.

Song Y.Y., Zhang Y., Ren H.N., Sun G.G., Qi X., Yang F., JiANG P., ZhaNG X., CUI J., WANG Z.Q. 2018b: Characterization of a serine protease inhibitor from Trichinella spiralis and its participation in larval invasion of host's intestinal epithelial cells. Parasit. Vectors 11: 499.

Sun G.G., Lei J.J., Guo K.X., Liu R.D., Long S.R., Zhang X., JiAnG P., CUi J., Wang Z.Q. 2019a: Primary assessment of a $T$. spiralis putative serine protease for early serological detection of Trichinella infection. Trop. Biomed. 36: 792-802.

Sun G.G., Lei J.J., Ren H.N., Zhang Y., Guo K.X., Long S.R., Liu R.D., Jiang P., Wang Z.Q., Cui J. 2019b: Intranasal immunization with recombinant Trichinella spiralis serine protease elicits protective immunity in BABL/c mice. Exp. Parasitol. 201: 1-10.

Sun G.G., Ren H.N., Liu R.D., Song Y.Y., Qi X., Hu C.X., YANG F., JiANG P., Zhang X., WANG Z.Q., CUI J. 2018a: Molecular characterization of a putative serine protease from Trichinella spiralis and its elicited immune protection. Vet. Res. 49: 59.

Sun G.G., Song Y.Y., Jiang P., Ren H.N., Yan S.W., Han Y., Liu R.D., Zhang X., Wang Z.Q., Cui J. 2018b: Characterization of a Trichinella spiralis putative serine protease. Study of its potential as sero-diagnostic tool. PLoS Negl. Trop. Dis. 12: e0006485.

Sun G.G., Wang Z.Q., Liu C.Y., Jiang P., Liu R.D., Wen H., Q X., WANG L., CUI J. 2015: Early serodiagnosis of trichinellosis by ELISA using excretory-secretory antigens of Trichinella spiralis adult worms. Parasit. Vectors 8: 484.

Tang F., Xu L., Yan R., Song X., Li X. 2012: Evaluation of the immune response induced by DNA vaccines expressing MIF and MCD-1 genes of Trichinella spiralis in BALB/c mice. J. Helminthol. 86: 430-439.

McVay C.S., Tsung A., Appleton J. 1998: Participation of parasite surface glycoproteins in antibody-mediated protection of epithelial cells against Trichinella spiralis. Infect. Immun. 66 : 1941-1945.

Wang J., Jiang Y., Yang W., Shi C., Huang H., Sun H., Liu G., Wang C., Yang G., CAI Y. 2018: Vaccination with DNA encoding ES $43-\mathrm{kDa} / 45-\mathrm{kDa}$ antigens significantly reduces Trichinella spiralis infection in mice. Res. Vet. Sci. 120: 4-10.

Wang L., Wang X., Bi K., Sun X., Yang J., Gu Y., Huang J., Zhan B., Zhu X. 2016: Oral vaccination with attenuated Salmonella typhimurium-delivered TsPmy DNA vaccine elicits protective immunity against Trichinella spiralis in BALB/c mice. PLoS Negl. Trop. Dis. 10: e0004952.

Wang Z.Q., Cui J., Wei H.Y., Han H.M., Zhang H.W., Li Y.L. 2006: Vaccination of mice with DNA vaccine induces the immune response and partial protection against $T$. spiralis infection. Vaccine 24: 1205-1212.

Wang Z.Q., Li L.Z., Jiang P., LiU L.N., CUi J. 2012: Molecular identification and phylogenetic analysis of Trichinella isolates from different provinces in mainland China. Parasitol. Res. 110: $753-757$.
WANG Z.Q., Zhang S.B., JiAng P., LiU R.D., LONG S.R., Zhang X., Ren H.J., CUi J. 2015: The siRNA-mediated silencing of Trichinella spiralis Nudix hydrolase results in reduction of larval infectivity. Parasitol. Res. 114: 3551-3557.

Wang B., Wang Z.Q., Jin J., Ren H.J., Liu L.N., Cui J. 2013: Cloning, expression and characterization of a Trichinella spiralis serine protease gene encoding a $35.5 \mathrm{kDa}$ protein. Exp. Parasitol. 134: 148-154.

Wu Z., Nagano I., Takahashi Y., Maekawa Y. 2016: Practical methods for collecting Trichinella parasites and their excretory-secretory products. Parasitol. Int. 65 (5 Pt B): 591-595.

Xu J., Bai X., Wang L.B., Shi H.N., van Der Giessen J.W.B., Boireau P., LiU M.Y., LiU X.L. 2017: Immune responses in mice vaccinated with a DNA vaccine expressing serine protease-like protein from the new-born larval stage of Trichinella spiralis. Parasitology 144: 712-719.

Xu J., Liu R.D., Long S.R., Jiang P., Zhang X., Cui J., Wang Z.Q. 2020: Characterization of a chymotrypsin-like enzyme from Trichinella spiralis and its facilitation on larva penetration of host's enteral epithelial cells. Res. Vet. Sci. 128: 1-8.

Xu J., Yang F., Yang D.Q., Jiang P., LiU R.D., Zhang X., Cui J., WANG Z.Q., 2018: Molecular characterization of Trichinella spiralis galectin and its participation in larval invasion of host's intestinal epithelial cells. Vet. Res. 49: 79.

Yang F., Yang D.Q., Song Y.Y., Guo K.X., Li Y.L., Long S.R., JIANG P., CUI J., WANG Z.Q. 2019: In vitro silencing of a serine protease inhibitor suppresses Trichinella spiralis invasion, development, and fecundity. Parasitol. Res. 118: 2247-2255.

Yang W., Li L.G., Liu R.D., Sun G.G., Liu C.Y., Zhang S.B., Jiang P., Zhang X., Ren H.J., Wang Z.Q., Cui J. 2015a: Molecular identification and characterization of Trichinella spiralis proteasome subunit beta type-7. Parasit. Vectors 8: 18.

Yang Y., Wen Y.J., Cai Y.N., Vallée I., Boireau P., Liu M.Y., Cheng S.P. 2015b: Serine proteases of parasitic helminths. Kor. J. Parasitol. 53: 1-11.

Zhang N., Li W., Fu B. 2018a: Vaccines against Trichinella spiralis: progress, challenges and future prospects. Transbound. Emerg. Dis. 65: 1447-1458.

Zhang S.B., Jiang P., Wang Z.Q., Long S.R., Liu R.D., Zhang X., YANG W., Ren H.J., Cui J. 2016: dsRNA-mediated silencing of Nudix hydrolase in Trichinella spiralis inhibits the larval invasion and survival in mice. Exp. Parasitol. 162: 35-42.

Zhang X., Xu L., Song X., Li X., Yan R. 2018b: Molecular cloning of enolase from Trichinella spiralis and the protective immunity in mice. Acta Parasitol. 63: 252-260.

Zhang X.Z., Sun X.Y., Bai Y., Song Y.Y., Hu C.X, Li X., Cui J., WANG Z.Q. 2020: Protective immunity in mice vaccinated with a novel elastase-1 significantly decreases Trichinella spiralis fecundity and infection. Vet. Res. 51: 43.

Zhang Y., WANG Z., Li L., CUi J. 2013: Molecular characterization of Trichinella spiralis aminopeptidase and its potential as a novel vaccine candidate antigen against trichinellosis in BALB/c mice. Parasit. Vectors 6: 246. 